This item was submitted to Loughborough's Research Repository by the author.

Items in Figshare are protected by copyright, with all rights reserved, unless otherwise indicated.

\title{
Exploring pedagogies of digital technology in physical education through appreciative inquiry
}

\section{PLEASE CITE THE PUBLISHED VERSION}

https://www.routledge.com/9780203704011

\section{PUBLISHER}

Routledge @ individual chapters, the contributors

\section{VERSION}

AM (Accepted Manuscript)

\section{PUBLISHER STATEMENT}

This work is made available according to the conditions of the Creative Commons Attribution-NonCommercialNoDerivatives 4.0 International (CC BY-NC-ND 4.0) licence. Full details of this licence are available at: https://creativecommons.org/licenses/by-nc-nd/4.0/

\section{LICENCE}

CC BY-NC-ND 4.0

\section{REPOSITORY RECORD}

Sargent, Julia, and Ashley Casey. 2019. "Exploring Pedagogies of Digital Technology in Physical Education Through Appreciative Inquiry”. figshare. https://hdl.handle.net/2134/33345. 
1 Title: Exploring pedagogies of digital technology in physical education through

2 appreciative inquiry.

$3 \quad \mathbf{1}^{\text {st }}$ Author/Corresponding Author: Julia Sargent ${ }^{1}$

4 ORCID ID: orcid.org/0000-0001-9082-8378

5 Contact email: j.sargent@lboro.ac.uk

6

$7 \quad 2^{\text {nd }}$ Author: Ashley Casey ${ }^{1}$

8 ORCID ID: orcid.org/0000-0002-8232-5727

9 Contact email: A.J.B.Casey@lboro.ac.uk

10

11 Affiliation:

12

${ }^{1}$ School of Sport, Exercise and Health Sciences, Loughborough University, Loughborough, UK.

\section{Abstract}

From a pedagogical perspective, what physical education (PE) teachers think, say and do with regards to digital technology has received little attention (Lupton 2015). This chapter examines a case study of 'Patrick', a UK PE teacher who embedded digital technology into his teaching. Using a case study approach guided by appreciative inquiry, this chapter draws on the views and experiences of Patrick, and others in his school, regarding digital technology use in an effort to understand the factors and experiences that influence how and 
The utilization of digital technology (henceforth called DigiTech) to support teaching and learning in education has grown dramatically in recent years. In the UK, this had led to increasing interest from subject areas such as PE and speculation over the potential future for teachers and students (see Future Foundation 2015). Recently, increased attention has been afforded to PE teachers' use and reflections of DigiTech (Casey et al. 2017b). Subsequently, there is an emergent picture of how DigiTech could be used in PE from a practical perspective.

From a pedagogical perspective, what PE teachers think, say and do with DigiTech has received little attention (Lupton 2015). Subsequently, little research has been conducted on PE teachers' views of DigiTech. This dearth of research results in a field that is increasingly well versed in discussions about how DigiTech could be used in PE. Worryingly, this lack of research means the field appears less competent and confident having discussions about how and why DigiTech is actually being used. Worryingly, little information exists about what shapes or contributes towards technology-orientated practices (Prestridge 2017). Consequently, a more complex understanding of pedagogy and the places were learning, teaching and context converge with DigiTech is required (Casey et al. 2017b).

This chapter reports on 'Patrick' (pseudonym). Patrick is a UK PE teacher who has embedded DigiTech into his practice. Our aim is to explore the views and experiences of Patrick regarding DigiTech use and to understand the factors and experiences that influence how and why he regularly uses DigiTech in his practice. Using a case study approach guided by appreciative inquiry, data are presented from life story interviews, interviews with colleagues (e.g. head teachers, IT managers, senior leadership and other PE teachers), lesson observations, field notes and school documentation. 
It is through exploratory steps, such as the ones we take in this chapter, that we can begin to appreciate PE teachers' experiences and use of DigiTech and how they attempt to use it pedagogically. Failure to address such areas means that the field is in danger of repeating conversations around specific types of DigiTech without appreciating the wider educational milieu in which it is situated (Selwyn 2017). Put differently, the chosen DigiTech is positioned unproblematically and is expected to work regardless of the context in which it is to be used (i.e. the social, cultural and economic realities of the school).This is particularly pertinent given the common rhetoric around the opportunities and challenge that lie behind the myths and rhetoric of DigiTech (Philips 2016). By viewing DigiTech in a more general and appreciative sense (by this we mean valuing and perceiving those factors that surround practice), rather than focusing on specific DigiTech devices, we can develop new insights to guide and challenge our thinking about teachers’ practices with DigiTech.

This chapter is presented in five sections. We first provide a brief discussion of the current literature base that links DigiTech, pedagogy and PE teachers. Second, we discuss the concepts of 'pedagogies of technology' and appreciative inquiry which underpin this chapter. Third, we discuss case study teacher, techniques used to generate data and grounded theory. Fourth, we explore Patrick's views and experiences regarding DigiTech use and the factors and experiences that influence his use. Finally, we offer some concluding remarks in relation to pedagogy and DigiTech and the implications of this work for PE researchers and practitioners.

\section{DigiTech in PE}

In recent years considerable growth in the availability and use of DigiTech in education has raised questions around what place DigiTech should have in different subject areas. PE is no exception. The pedagogical relationship between DigiTech and PE is particularly important 
given discipline specific technologies such as video-analysis, wearable devices and active video games (Enright et al. 2017). The use of different types of DigiTech by students and teachers in PE has been the focus of many research studies. A small sample of DigiTech research includes: Exergaming (e.g. Meckbach et al. 2013), the Nintendo Wii Fit (e.g. Perlman et al. 2012), DartFish software, heart rate monitors, pedometers, CD players (Juniu, 2011; Thomas and Stratton, 2006) and wikis (Hastie, Casey and Tarter, 2010). Our focus however, is not to engage in debates around the potential or current benefits of apps or specific devices for PE. Instead, and despite the increasing availability of DigiTech hardware and resources to support use, many questions pertaining to such use still exist (Krause, Franks and Lynch 2017). Research has focused on isolating the hardware (the technological device) rather than the ideas of the teacher behind its use. Arguably, one of the reasons DigiTech has not become customary or commonplace in PE may be a lack of focus on the pedagogy behind the use of DigiTech (Casey et al. 2017b).

Less prominent, but nonetheless emergent discussions have been held which explore the opportunities for DigiTech use (Casey et al. 2017b) and teachers’ experiences of using DigiTech in their classrooms (Goodyear et al. 2014; Kretschmann 2015). Bodsworth and Goodyear (2017) found barriers such as pupils’ expectations for learning, school technological restrictions and the introduction of a new pedagogical approach limited the use of DigiTech. Similar obstacles are also explored by Gibbone, Rukavina and Silverman (2010) who found that understanding the contextual factors that influencing use is a necessary foundation to furthering our understanding of the challenges pertinent to PE as a unique context. Consequently, there are many factors that influence how and why DigiTech is utilised in PE. 
Through research we are made aware of need to better consider the teacher and their uses of DigiTech in PE. So much so that it "appears that it is the teacher rather than the technology that influences digital technology use in schools” (Starkey, 2011, p.24). Pedagogical practice involving DigiTech is, therefore, also a "personalised pedagogy” (Calderon et al. 2017, p.100). In particular, pedagogy involving DigiTech involves “practitioners making critical and intelligent decisions about why, how and when to use (and not use)” DigiTech (Fletcher et al. 2017, p.114). Given this personalisation and the critical role of the teacher, it is concerning that there is a dearth of literature exploring how practices with DigiTech are shaped or change over time (Prestridge 2017). Pedagogical beliefs will be constantly confronted and challenged by the growth of DigiTech (Sinclair 2009). Thus, it is even more important that, as researchers and practitioners, we consider the on-going relationship between DigiTech and teachers and their pedagogical practices.

\section{Pedagogies of technology}

Due to the pedagogical focus of this chapter, and the belief that pedagogy will be challenged by the growth of DigiTech, it is important to reflect on existing literature. When referring to 'pedagogy', a term which possesses a variety of definitions, applications and meanings, we are referring to the connections between teachers and their teaching, learners and their learning and knowledge in context (Armour 2011).

In the same way that neither DigiTech, or our debates about its use, are something 'new', the call for a pedagogical rather than a technological goal for integrating DigiTech in education is also not a new argument (Casey 2014a). Watson (2001) argued that the cart had been placed before the horse in regard to pedagogy and DigiTech. In other words, decisions to use DigiTech have largely been driven by hardware and software rather than a pedagogical 
process. This is concerning because any DigiTech used by a teacher is influenced by the factors of curriculum, teaching and learning that surround its use.

In positioning the concept of 'pedagogies of technology' in this chapter we are conscious of the perception that the two terms may be back to front. Placing pedagogy before technology reflects our wish that, as field, we consider "how we want to teach before we consider the technological means that we use to accomplish it” (Dron 2012, p.25). In other words, to emphasise how DigiTech is used (pedagogy), not just what is used (technology).

In their recent book, Casey et al. (2017b, p.6) used a pedagogical cases framework to explore individual PE practitioner's narratives around how and why they have used DigiTech. Each narrative is analysed by multidisciplinary experts to unpick the teacher's pedagogical approach to DigiTech. They defined pedagogies of technology as:

critically aware and technically competent pedagogies that can be developed in practice to maximise the latent potential of technologies to accelerate learning in meaningful ways that meet the individual needs of diverse learners. The starting point for a pedagogy of technology is a desire to do things differently, rather than to do the same things using 'flashy' tools and gizmos.

In this chapter, pedagogies of technology are explored through Patrick's developing use of DigiTech in his teaching. In seeking to examine Patrick’s desire to "do things differently" (both in terms of teaching and learning) and explore his developing practice we used appreciative inquiry because it allowed us to appreciate the nuances of DigiTech use (i.e. techniques and sources of information) that aided his teaching and his students' learning.

\section{Appreciative Inquiry}


Appreciative inquiry was conceptualised in the field of organisational development and has been defined in different ways. Appreciative inquiry is a strengths-based approach which seeks to illuminate the elements and factors in an individual and organisations practice that they believe enabled success (Pill 2015). Appreciative inquiry, for our purposes, is viewed in alignment with scholars such as Enright et al. (2014) and Watkins and Cooperrider (2000) as a philosophy rather than a specific set of techniques, methods or methodology. From this perspective, appreciative inquiry is viewed as an orientation grounded in identifying strengths rather than weaknesses. This perspective is underpinned by the belief that every culture, and every person in that culture, has strengths that can be amplified. This chapter is therefore concerned with the identification and exploration of aspects of Patrick's practice that he believed contributed to his success with DigiTech.

Building upon the emergent work of Gray, Treacy and Hall (2017), Pill (2015) and Hill et al. (2015), our application of appreciative inquiry uses a ‘4-D’ (discovery, dream, design and destiny) cycle (Cooperrider and Whitney’s 2001):

(1) Discovery. In this stage participants identify, reflect on and discuss the reasons why they believe practice has worked 'best' or 'efficiently'.

(2) Dream. During this stage participants are asked to imagine themselves, their group, or community at its best and attempt to identify what could be.

(3) Design. Having identified common aspirations or a common dream, participants are questioned to explore what the ideal situation would be.

(4) Destiny. This stage is concerned with exploring what will be and working with participants to explore how the 'best' could be sustained.

Appreciative inquiry philosophy can take varied paths and forms in research and one of its perceived strengths is that it can be adapted to a particular culture, context and environment 
170 (Preskill and Catsambas 2006). Irrespective of context, however, the appreciative interview remains at the heart of the process (Cooperrider and Whitney 2001; Enright et al. 2014; Michael 2005). Appreciative interviewing forms the basis of the discovery phase and is often the impetus for further inquiry. Therefore, while appreciative inquiry is not a technique or method, there are methods and questions which are more aligned with the approach (Hill et al. 2015). The appreciative interview helps to bring to new data to light which highlight experience, values and strengths that can be collectively shared (Watkins and Cooperrider 2000). Appreciative interviews differ from traditional interviews because rather than soliciting facts and opinions, these interviews seek examples, stories and metaphors (Shuayb et al. 2009). The purpose is to find the best moments, events and stories rather than fixating on a problem or area that needs solving. For example, discovering the strengths, resources and capabilities of Patrick's practice (e.g. 'what do you see as being some of the causes of success to your teaching with technology?' and 'what highlights have occurred for you when using technology in your teaching?').

Enright et al. (2014) argue that PE and sports pedagogy scholars have sought to identify and understand what's broken in PE creating a deficit based discourse. This perspective, in turn, has had a considerable influence on practice and how we consider topics such as pedagogy (Gray, Treacy and Hall 2017). Conversely, instead of focusing on what is ‘broken’ or ‘failing' regarding DigiTech use, the emphasis through appreciative inquiry is driven by the desire to uncover and appreciate 'what works' for an individual. The focus is therefore around how and why Patrick believes that DigiTech has aided him in his practice and appreciating how he developed/is developing his pedagogy of technology. 
Patrick volunteered for this study and was selected as a case study based on his self-identified use of DigiTech. At the time of the study, Patrick (age 35-40) had been teaching PE at Newton school (pseudonym) for 10 years and had been head of department for 4 years. Patrick had remained at the same school since qualifying as a teacher. His use of DigiTech has varied over time but was now a regular part of his everyday teaching. Patrick had a strong belief in the value of DigiTech, developed his ideas through Twitter and shared his practice with others at his school.

\section{School setting}

Newton school is a community college (11-18 years) in a small town in the North East of England. Newton is a co-educational school with a large proportion of White British students and a small proportion of students for whom English is an additional language. It also has a high proportion of students eligible for pupil premium. Newton has a PE department of 9 full time PE teachers.

PE is a compulsory subject at Newton and students have an allocated hour a week on their timetables. Programmes for compulsory PE are structured through a multi-activity approach and the National Curriculum. This compromised of 'main activities' (e.g. Rugby and Netball), 'additional activities’ (e.g. Dodgeball and Tchoukball) and fitness activities (e.g. HITT and Boxercise).

Using DigiTech to support teaching and learning underpins many of Newton’s visions and priorities. For example, in a rolling programme, each pupil in Year 7 (age 11-12) was given an iPad at the start of the academic year. This is in addition to each department having a set of iPads and every staff member having their own device. 
Data were generated by the first author using a variety of qualitative methods. These included four themed interviews guided by appreciative inquiry, school visits involving interviews with colleagues (e.g. headteacher, senior leadership team member, IT manager and PE teachers), follow up interviews, lesson observations, field notes and document analysis.

\section{How did we analyse our data?}

Data analysis was conducted using a constructivist approach to grounded theory. Constructivist grounded theory involves coding techniques that facilitate the analysis of actions and processes that are grounded in the data, but also acknowledges the existence of multiple social realities and the flexibility of the approach. Using Charmaz's (2014, p.15) criteria as a guide, data gathering and analysis were iterative in nature but involved a continuous shift between coded data and new data collection, analysis and coding, to trace and examine Patrick's practice. Both initial and focused coding was used to identify and refine key action and concepts which was further facilitated by memo writing. This constructivist approach can be characterised as a process of 'constant comparison' (Glaser and Strauss 1967), which involved comparing data and developing analytic categories.

\section{Findings and Discussion}

Three main themes were constructed from the data analysis: 'Working within an embedded culture of DigiTech use', 'establishing routines' and 'keeping tasks simple'. The first theme 'working within an embedded culture of DigiTech use' shows how Patrick, the department and the school have developed a culture around being forward thinking and sharing ideas regarding DigiTech that they embedded into practice. The second theme, 'establishing routines' identifies how developing consistent routines of practice were vital in supporting both student and teacher learning with DigiTech. The third theme, 'keeping tasks simple' 
highlights how using simple strategies in certain scenarios allowed Patrick to increase the students' physical activity and support the needs of his learners.

\section{Working within an embedded culture of DigiTech use}

At both an individual and department/school level, a culture around the use of DigiTech was established and embedded. On an individual level, Patrick identified that his own developing culture consisted of his interest, being forward thinking and keeping up to date with DigiTech. Patrick self-identified as being forward thinking and suggested that this was one of the factors promoting his use of DigiTech. He felt that this stemmed from his interest in DigiTech. In defining this term, Patrick explained that forward thinking was being: “Happy to try new things, happy to change, happy to trial and then if things aren’t working, happy to say why”.

Patrick felt that forward thinking was quite natural because of his sporting background and an enduring aim to be innovative and creative in his teaching. This was similarly commented on by other colleagues who identified Patrick as "being ahead of the game", "thinking outside the box" and "being proactive-always thinking what's next?"

The starting point for a pedagogy of technology is a desire to do things differently (Casey et al. 2017b) and accepting that mistakes will be made; something that Patrick clearly exhibited. Whilst Patrick positioned himself as forward thinking, we do not suggest that this always equated to pedagogical development. That said, he felt that by looking forwards and keeping up to date with latest ideas and practices through social media he was constantly developing as a teacher. Similar to Armour et al. (2017), Patrick saw it as a professional responsibility to find new ways to support learning. Searching through Twitter was a particularly beneficial 
practice for Patrick and, as purported by Gleddie et al. (2017), was a powerful tool for engaging in purposeful professional development. For Patrick using Twitter was pertinent as:

"Teachers are always that little bit further behind so it is important to find out what the kids are interested in and how you can use that and bring it into teaching”.

On a department/school level, a developed culture was similarly established around being forward thinking but also sharing as a form of professional development and having consistent strategies around DigiTech use. An example of a whole school approach appears in school documents/policy as "embedding technology into pedagogical strategies" and "the development of a 'new technologies culture' of teaching and learning”. Specifically, in a document explaining the overview of their recent iPad project, the school stated that they developed their own 'i-Pedagogy”. This was built around the use of "top apps” and 'Blooms Taxonomy. ${ }^{1}$. Subsequently, the culture of DigiTech use in the school was underpinned by pedagogy and the consideration of what pieces and uses of DigiTech could be applied.

Patrick, in considering these approaches, embedded the use of the Showbie ${ }^{2}$ app to allow students to apply and create work for assessment. This was supported not only through the accessibility of technology but also in the consistency of sharing as a form of development. A continuous professional development (CPD) structure involved staff being willing to try and share ideas and learn through trial and error. This culture resulted in "everybody singing off the same hymn sheet” and Patrick noting, both in the school and in his department, that:

\footnotetext{
${ }^{1}$ Using Bloom's (1956) taxonomy of educational objectives (i.e. remember/understand, apply, analyse, evaluate and create) the school mapped different apps and the ways they could be used towards these objectives.

${ }^{2}$ Showbie is an app that provides a platform for students to create, annotate and share documents.
} 
“If things didn’t work we had a culture, we had a relationship amongst everybody to be brave enough to say actually we don't like this. It doesn’t work. What are we going to do about it? We'd come up with a new idea and implement it”.

As shown in the literature, sustained CPD is important (see Patton, Parker and Pratt 2013) and would seem synonymous with forward thinking around DigiTech. The culture established by both Patrick and the department/school was viewed by many colleagues as important in supporting DigiTech use. The head teacher identified that Patrick had "grown up in the culture and developed within the culture of the college”. In this sense Patrick's established practices of being forward thinking and keeping up to date formed a supportive and consistent infrastructure around which he could develop his practice. As such, they formed a key foundation of his pedagogy of technology. Tondeur et al. (2008) posited the DigiTech policies and the views of the school have a significant effect on an individual's use of DigiTech. With a culture of technology from Patrick and the school being in alignment, this was seen as important in ensuring that both Patrick and the students could see the value of DigiTech.

Literature suggests that most teachers lack organisational support to integrate DigiTech effectively (Fullan 2013) and under such conditions, teachers can fail to think pedagogically about technology (Casey et al. 2017b). However, what Patrick's case suggests is that when the individual and culture they work in support and encourage "do[ing] things differently", a creative environment is fostered. This environment serves as a catalyst that helps teachers to develop pedagogies of technology. Factors such as regular CPD, consistent pedagogical ideas, leadership and supporting teachers' exploration of DigiTech, aid and influence the developing creativity. 
Establishing routines around DigiTech for teaching and learning was vital for Patrick to ensure that students did not see DigiTech as a "novelty". Patrick suggested that "as soon as your routines and expectations are embedded...for me it doesn’t become a gimmick”, a suggestion that was echoed in the interview with a member of the school's senior leadership team. The routine nature of his practice meant that the pedagogical strategies utilised became consistent and were part of the normal practice culture. They were familiar to Patrick and his students:

"It's those little routines and practices that you put in place that they [the students] follow and it's the same with the iPads... as that process becomes more familiar to them it makes it more efficient”.

Drawing upon the work of Selwyn (2013) establishing consistent routines enabled Patrick and his students to teach and learn in more efficient ways. This example of practice corroborates the idea of Goodyear et al. (2017) whereby frequent, specific and repeated practice allow teachers (and in this case Patrick) to "support learning” "offer individualised support" and "stretch and challenge" students learning. Thus, these findings support Goodyear et al.’s (2017, p. 25) conclusion that “technology can be used to promote studentcentred learning activities”.

One pedagogical strategy Patrick’s regularly used was flipped learning. Whilst flipped learning is not a pedagogical approach specific to DigiTech, for Patrick it was a consistent pedagogical strategy implemented by both the school and Patrick to support his use of DigiTech: 
“[Flipped learning] makes the lesson longer by using ICT to extend the lesson...I could take a little video clip, share it with them and I could actually emphasise the points based on the lesson ready for the next one”.

This allowed Patrick and other staff members to "maximise learning time" because the home work “directly linked to the next lesson so it's like a journey... they [the students] can see the progress”. In explaining his use of flipped learning in PE further, Patrick elucidated:

"It was a case of a 50-minute lesson becoming an hour and 20 minutes because I was expecting them to do a 30-minute piece of homework...little Google forms...kahoot quiz would be the flipped learning resource ready for the next lesson. Straight away their homework was purposeful in my eyes; it has got a link to the lesson”.

Similar to Østerlie (2016) and Roth (2014), Patrick found that flipped learning can increase levels of physical activity because you can start the lesson immediately with practical activity as the students have conducted the explanation and understanding in their homework. The 50minute lesson time could therefore be used more "efficiently and effectively" by establishing the routine of flipped learning. How flipped learning was delivered through two types of

DigiTech is explored in the table below:

\begin{tabular}{|l|l|l|}
\hline $\begin{array}{l}\text { Type of } \\
\text { DigiTech } \\
\text { (App/Device) }\end{array}$ & Functions/Description & How it was/has been used \\
\hline Showbie (app) & $\begin{array}{l}\text { App used to create a platform for } \\
\text { students to share work, annotate } \\
\text { document/pictures and teachers to } \\
\text { mark and give a variety of feedback. } \\
\text { Accessed on iPad device. }\end{array}$ & $\begin{array}{l}\text { Support workflow and } \\
\text { communication with students. }\end{array}$ \\
& $\begin{array}{l}\text { Capturing and submitting work (i.e. } \\
\text { videos) for assessment - aided } \\
\text { physical skill development. }\end{array}$ \\
& $\begin{array}{l}\text { Used in conjunction with other apps } \\
\text { such as coach's eye and book } \\
\text { creator. } \\
\text { Mobile nature of app on device } \\
\text { ideal for PE. }\end{array}$ \\
\hline
\end{tabular}




\begin{tabular}{|l|l|ll|}
\hline Padlet (online) & Online message board where users & - $\begin{array}{l}\text { Used by Patrick to post questions } \\
\text { for students to answer and videos to } \\
\text { can post and have discussions on a } \\
\text { virtual message wall. }\end{array}$ & $\begin{array}{l}\text { reflect upon for homework - aiding } \\
\text { video analysis techniques. }\end{array}$ \\
& - $\begin{array}{l}\text { Students posting answers and } \\
\text { discussion points based on viewing } \\
\text { a video. }\end{array}$ \\
\hline
\end{tabular}

346

Whilst the use of flipped learning to supplement activity time was an established strategy, Patrick used a variety of different methods within this approach. This was illustrated when Patrick discussed how students could choose an app to reach the learning objective:

They [the students] could present work in a different way, whether it's a poster, a piccolage or comiclife, the end product, the outcome is the same but the tool that they've used is different.

The variety of methods used in flipped learning meant that Patrick was constantly engaging in the assessment of students learning needs. Importantly, evidence from the local context (i.e. the practice occurring in the broader school) was used to drive his pedagogical actions (Goodyear et al. 2017). Patrick’s use of technology through flipped learning provided students with an environment where learning was an active process (occurring both inside and outside the school) whereby both teacher and student are involved in knowledge construction (Parker et al. 2017). In this sense Patrick was able to develop a pedagogy of technology which contributed in meaningful ways to meeting the needs of his learners.

\section{Keeping tasks simple}

Patrick expressed that the rationale behind his use of DigiTech, and why he believed it “worked” for his teaching, was "keeping it simple”: 
“Trying too much in different ways creates more challenge. I’ve just got a couple of simple methods that I believe work at this moment in time and actually they work better every year”.

Examples of “simple” practice were replete in school documents, lesson observations and interviews. For Patrick, identifying instances where DigiTech “lent itself” to trying simple DigiTech ideas was important. This included spending time to get students to understand "how to use an app", showing performance videos in the changing rooms while students were getting changed and using apps in rest periods to assess learning. Patrick supported less physically able learners by engaging them with videos and performance analysis questions on an iPad. For Patrick, this was more than "ticking the ICT box but ticking the learning box as well because they are actively learning at the same time". The students were "resting for a minute but they were learning or their mind was actively engaged on the task for that time”. Similar to Armour et al. (2017, p.215), Patrick used iPads to add “pedagogical excitement” with different groups of students to supplement their physical activity time. These practices are consistent with those in Armour et al. (2017) case study where the teacher endeavoured to focus on the learning rather than the teaching and tried to make learning interesting, relevant and personalised to meet the needs of each student. Thus, it was apparent in speaking to Patrick that he had identified key outcomes (i.e. reflecting on performances) for students to achieve before considering the means to achieve them. When considering DigiTech from this pedagogical perspective, iPads could be used in a way that was "engaging students and not being used as a gimmick”.

A simple practice to ensure that learning is at the forefront might be allowing students to choose the type of equipment they would like to use to complete a task (Baert et al. 2017). Patrick explained how this involved "chunking it [getting students using apps] into little stages" to "let them become masters or experts in that app”. In this sense Patrick scaffolded 
the use of DigiTech to ensure that students could take control of their own learning but were not inhibited by a lack of technological knowledge. Whilst the pedagogical vision might seem simple to achieve, the realities of the pedagogical use of DigiTech requires consideration of the preferences and skills of the student so that the learning outcome is not lost (Fletcher et al., 2017). In this regard, Patrick had clearly considered the learner and their learning, how to best deliver the content and the context in which this occurred. As conceptualised by Casey et al. (2017), it is important to keep (or make) ideas simple if they are to stick and impact the practices of others (i.e. students). The idea of 'keeping things simple' ensured that that pedagogy was at the forefront of Patrick's use of DigiTech and was a part of his routines of practice.

\section{Concluding Remarks}

From a pedagogical perspective, what PE teachers think, say and do with regards to DigiTech has received little attention (Lupton 2015). In this chapter, we have provided an exemplar of how and why DigiTech is actually being used. In unpicking our understanding of pedagogies of technology as a concept for this chapter and, therefore, the spaces where teaching, learning and context converge, we have sought to appreciate how Patrick uses DigiTech in ways that aid both teaching and learning.

In considering Patrick and his teaching, DigiTech has allowed Patrick to be innovative and creative whilst also considering the interest of his learners. In foregrounding the learner and their learning, Patrick had clearly considered the students expectations for learning and how DigiTech could be used to support their physical activity. This may, in some cases, involve starting with relatively 'simple' tasks and ideas which allow the teacher to support, (re)direct or assess the learning with DigiTech. It was only then that Patrick could use DigiTech as an 
414 aid to himself and his students in ways that were meaningful. In considering knowledge in the context of PE, we are struck by Patrick's ability to relate to his institutional context in a way that meets his own and his students' needs. Teaching is never seen to occur in a void (Quennerstedt 2017), but often it would seem, when concerning DigiTech, that we often fail to appreciate the wider milieu in which a pedagogy of technology can operate (Selwyn 2017). In essence, DigiTech 'worked’ for Patrick because it was underpinned by establishing strategies beyond the "initial period of delight” (Casey 2014b, p.30) and developing them into the working practice of both Patrick and the school.

In reflecting upon the practical implications of our work, we are aware of the need (both as researchers and practitioners) to develop a knowledge-base about what teachers learn, do and practice in order to create effective policies, training programmes and support practice. This is because it is 'how' practices are interpreted and negotiated between schools, practitioners and in the classroom that determine how they are developed and used. These should be considered as key influencers in the pedagogical use of DigiTech.

Of course we are also aware of the challenges associated with a pedagogical approach to DigiTech e.g. the speed of innovation, the volume of 'potential' ideas, or pupils' expectations for learning digitally. These challenges can equate to teachers' developing concerns for, or fears of, using DigiTech. However, this encourages us, as researchers and practitioners, to "be brave” in our thinking (Casey et al. 2017b, p.250). This also involves consideration of what can be controlled and established. In the case of Patrick (and his personalized pedagogy of technology), this involved developing an attitude and approach that had established support networks and ensuring routines that allowed him to use DigiTech in simple but effective ways. In a more general sense, we have learnt that in order for DigiTech to become customary or common place in PE our focus must be on the pedagogy. Questioning at all times what outcomes DigiTech can help us to achieve rather than being driven by gimmicks 
seems key. Reflecting upon the outcomes of our use of DigiTech in relation to pedagogy is therefore important. Pedagogies of technology are not only about what is used or how

DigiTech is used but also what is achieved. In this way, the focus shifts from teachers using DigiTech to student learning through DigiTech. We must remember, nonetheless, that this is an on-going relationship; one where DigiTech is considered as part of the journey and not just the final destination.

\section{Further reading:}

Prestridge, S., 2017. Examining the shaping of teachers' pedagogical orientation for the use of technology. Technology, Pedagogy and Education, p.1-15.

This paper provides insights into teacher beliefs that influence the use of DigiTech.

Villalba, A., Gonzalez-Rivera, M. and Diaz-Pulido, B., 2017. Obstacles perceived by Physical Education teachers to integrating ICT. The Turkish Online Journal of Educational Technology, 16(1), pp. 83-92.

This quantitative study (based in Turkey) analyses the perception of physical education teachers regarding obstacles to integrating DigiTech.

Casey, A., Goodyear, V.A. and Armour, K.M., 2017. Digital Technologies and Learning in Physical Education: Pedagogical cases. London: Routledge.

This collection of case studies on PE practitioners explains how and why DigiTech is used in their practice.

\section{Review Questions:}


1. Using the recommended readings as support, what do you think are the steps required to develop a pedagogy of technology for PE?

2. What strategies would you consider in sustaining the use of DigiTech beyond the initial period of enthusiasm for you and your students?

3. Can you identify any situations in your own practice where it could be appropriate to try and implement DigiTech? Remember if a situation would be best served by the use of zero technology then that's still a pedagogical decision!

\section{References}

Armour, K., 2011. Sport pedagogy: an introduction for teaching and coaching. Essex: Pearson.

Armour, K., Evans, G., Bridge, M., Griffiths, M. and Lucas, S., 2017. Gareth: the beauty of the iPad for revolutionising learning in physical education. In: Casey, A., Goodyear, V. and Armour, K. ed. Digital Technologies and Learning in Physical Education: Pedagogical cases. London: Routledge, pp.213-231.

Baert, H., Winiecki, T., Madden, M., Bryan, R. and MacDonald, C., 2017. Tom: using digital technology in physical education to transform pedagogy. In: Casey, A., Goodyear, V. and Armour, K. ed. Digital Technologies and Learning in Physical Education: Pedagogical cases. London: Routledge, pp.191-213.

Bodworth, H. and Goodyear, V., 2017. Barriers and facilitators to using digital technologies in the Cooperative Learning model in physical education. Physical Education and Sport pedagogy.

Calderon, A., Lopez-Chicheri, I., Fernandez-Rio, J. and Sinelnikov, O., 2017. Antonio: “I 
really want them to be engaged and learn”. The use of social media in higher education. In: Casey, A., Goodyear, V. and Armour, K. ed. Digital Technologies and Learning in Physical Education: Pedagogical cases. London: Routledge, pp.86-104.

Casey, A., 2014a. Rethinking IT in physical education: Pedagogy before technology. Cultura, Ciencia y Deporte, 9(25), pp.3-4.

Casey, A., 2014b. Models-based practice: great white hope or white elephant? Physical Education and Sport Pedagogy, 19(1), pp.18-34.

Casey, A., Goodyear, V.A. and Armour, K.M., 2017a. Rethinking the relationship between pedagogy, technology and learning in health and physical education. Sport, Education and Society, 22(2) pp. 228-304.

Casey, A., Goodyear, V.A. and Armour, K.M., 2017b. Digital Technologies and Learning in Physical Education: Pedagogical cases. London: Routledge.

Charmaz, K., 2014. Constructing grounded theory. $2^{\text {nd }}$ ed. London: Sage.

Cooperrider, D.L. and Whitney, D., 2001. A positive revolution in change: Appreciative Inquiry. Public administration and public policy, 87, pp.611-630.

Dron, J., 2012. The pedagogical-technological divide and the elephant in the room. International Journal on E-Learning, 11(1), pp.23-38.

Enright, E., Hill, J., Sandford, R. and Gard, M., 2014. Looking beyond what’s broken: towards an appreciative research agenda for physical education and sport pedagogy. Sport, Education and Society, 19(7), pp.912-926.

Enright, E., Robinson, J., Hogan, A., Stylianou, M., Hay, J., Smith, F. and Bell, A., 2017. Jarrod: the promise and messy realities of digital technology in physical education. In: Casey, 
A., Goodyear, V. and Armour, K. ed. Digital Technologies and Learning in Physical Education: Pedagogical cases. London: Routledge, pp. 173-191.

Fletcher, T., Vasily, A., Bullock, S.M., Kosnik, C. and Ni Chroinin, D., 2017. Andy: blogging with students. Educational visions and digital realities. In: Casey, A., Goodyear, V. and Armour, K. ed. Digital Technologies and Learning in Physical Education: Pedagogical cases. London: Routledge, pp.104-121.

Fullan, M., 2013. Stratosphere: Integrating technology, pedagogy and change knowledge. Toronto: Pearson.

Future Foundation, 2015. The Class of 2035: Promoting a brighter and more active future for the youth of tomorrow [online]. London: Future Foundation.

Gibbone, A., Rukavina, P. and Silverman, S., 2010. Technology integration in secondary physical education: Teachers attitudes and practice. Journal of Educational Technology Development and Exchange, 3(1), pp.27-42.

Glaser, B.G. and Strauss, A.L., 1967. The discovery of grounded theory: Strategies for Qualitative Research. Hawthorne, NY: Aldine.

Gleddie, D., Feith, J., Howe, D., Larsson, H., Cale, L. and Casey, A., 2017. Joey: social media as a tool for professional development. . In: Casey, A., Goodyear, V. and Armour, K. ed. Digital Technologies and Learning in Physical Education: Pedagogical cases. London: Routledge, pp.121-137.

Goodyear, V.A., Blain, D., Quarmby, T. and Wainwright, N., 2017. Dylan: the use of mobile apps within a tactical inquiry approach. In: Casey, A., Goodyear, V. and Armour, K. ed. Digital Technologies and Learning in Physical Education: Pedagogical cases. London: Routledge, pp.13-31. 
Goodyear, V.A., Casey, A. and Kirk, D., 2014. Tweet me, message me, like me: using social media to facilitate pedagogical change within an emerging community of practice. Sport, Education and Society, 19(7), pp.927-943.

Gray, S., Treacy, J. and Hall, E., 2017. Re-engaging disengaged pupils in physical education: An appreciative inquiry perspective. Sport, Education and Society, DOI: $10.1080 / 13573322.2017 .1374942$

Hastie, P.A., Casey, A. and Tarter, A.M., 2010. A case study of wikis and student-designed games in physical education. Technology, Pedagogy and Education, 19(1), pp.79-91.

Hill, J., Sandford, R. and Enright, E., 2015. 'It has really amazed me what my body can now do': boundary work and the construction of a body-positive dance community'. Sport in Society, 19(5), pp.667-679.

Juniu, S., 2011. Pedagogical uses of technology in physical education. Journal of Physical Education, Recreation and Dance, 82(9), pp.41-49.

Krause, J., Franks, H. and Lynch, B., 2017. Current technology trends and issues among health and physical education professionals. The Physical Educator, 74, pp.164-180.

Kretschmann, R., 2015. Physical education teachers’ subjective theories about integrating information and communication technology (ICT) into physical education. TOJET: The Turkish Online Journal of Educational Technology, 14(1), pp.68-96.

Lupton, D., 2015. Data assemblages, sentient schools and digitised health and physical education (response to Gard). Sport, Education and Society, 20(1), pp.122-132.

Meckbach, J., Gibbs, B., Almqvist, J., Ohman, M. and Quennerstedt, M., 2013. Exergames as a teaching tool in physical education? Sport Science Review, XXII (5-6), pp.269-385. 
Østerlie, O., 2016. Flipped learning in physical education: why and how? In: Novak, D., Antala, B. and Knjaz, D. ed. Physical Education and New Technologies, Zagreb: Croatian Kinesiology Association, pp.166-176.

Parker, M., Morrison, J., Patton, K., Babkes Stellino, M., Hinchion, C. and Hall, K., 2017. Jamie: “I couldn’t teach without technology”: A teacher and student learning journey. In: Casey, A., Goodyear, V. and Armour, K., Digital Technologies and Learning in Physical Education: Pedagogical cases. London: Routledge, pp.31-49.

Patton, K., Parker, M. and Pratt, E., 2013. Meaningful learning in professional development: Teaching without telling. Journal of Teaching in Physical Education, 32, pp.441-459.

Perlman, D., Forrest, G. and Pearson, P., 2012. Nintendo Wii: Opportunities to put the education back into physical education. Australian Journal of Teacher Education, 37(7), pp. 85-94.

Phillips, M., 2016. Re-contextualising TPACK: Exploring teachers’ (non-)use of digital technologies. Technology, Pedagogy and Education, 25(5), pp.555-571.

Pill, S., 2015. Using appreciative inquiry to explore Australian football coaches’ experience with games sense coaching. Sport, Education and Society, 20(6), pp.799-818.

Preskill, H. and Catsambas, T., 2006. Reframing evaluation through appreciative inquiry. Thousand Oaks: Sage.

Prestridge, S., 2017. Examining the shaping of teachers' pedagogical orientation for the use of technology. Technology, Pedagogy and Education, DOI:10.1080/1475939X.2016.1258369.

Roth, K., 2014. Technology for tomorrow’s teachers. Journal of Physical Education, Recreation and Dance, 85(4), pp.3-5. 
574 Selwyn, N., 2013. Distrusting educational technology: Critical questions for changing times.

575 London: Routledge.

576 Selwyn, N., 2017. Educational technology: Key issues and debates, $2^{\text {nd }}$ ed. London:

577 Bloomsbury.

578 Shuayb, M., Sharp, C., Judkins, M. and Hetherington, M., 2009. Using appreciative inquiry

579 in Educational Research: Possibilities and Limitations. Slough, UK:National Foundation

580 Educational Research Report.

581 Sinclair, A., 2009. Proactive pedagogies in e-Learning: Making the invisible visible.

582

International Journal of Teaching and Learning in Higher Education, 21(2), pp.197-209.

583 Starkey, L., 2011. Evaluating learning in the $21^{\text {st }}$ century: A digital age learning matrix.

584 Technology Pedagogy and Education, 20(1), pp.19-39.

585

586

587

588

589

590

591

592

593

594

Tearle, P. and Golder, G., 2008. The use of ICT in the teaching and learning of physical education in compulsory education: how do we prepare the workforce of the future? European Journal of Teacher Education, 31(1), pp.55-72.

Thomas, A. and Stratton, G., 2006. What we are really doing with ICT in physical education: A national audit of equipment, use, teacher attitudes, support, and training. British Journal of Educational Technology, 34(4), pp.617-632.

Tondeur, J., van Keer, H., van Braak, J. and Valcke, M., 2008. ICT integration in the classroom: Challenging the potential of a school policy. Computers and Education, 51(1), pp.212-223.

Watkins, J. and Cooperrider, D., 2000. Appreciative inquiry: A transformative paradigm. Journal of the Organisational Development Network, 32(1), pp.6-12. 
596 Watson, D.M., 2001. Pedagogy before technology: Rethinking the relationship between ICT 597 and Teaching. Education and Information Technologies, 6(4), pp.251-266.

598 